\title{
A Study on Plasmin Substances in Human Saliva
}

\author{
by \\ Kineshiro NAGAI, ${ }^{*}$ Katsuhito TSUCHIYA, ${ }^{*}$ \\ Hirotake AGARIGUCHI, A Akinobu SANO* \\ and Akira YAZAKI*
}

A study concerning plasmin substances was early initiated with the efforts of DASTREE [1] who found that once coagulated blood would liquify in vitro without any bacterial contamination, and he called this phenomenon as fibrinolysis. Later, NOLF experimentally confirmed the fact that by injecting pepton into dogs whose liver was extracted it was possible to promote this fibrolysis. Rapid advances have been recently made in this and other areas associated with fibrinolysis and as a result, the so-called plasmin substances containing plasminogen, plasmin, proactivator, activator, antiplasmin, etc. [2, 3, 4]. Existence of these substances has given rise to clinical value connected with the problems of bleeding in surgical operations, those in gynecological area, the development of anaphylaxy, etc.

These substances are now regarded as having the following scheme of transference.

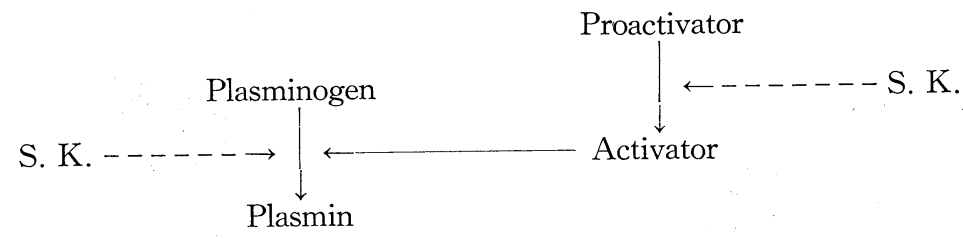

ALBRECHTSEN reported on the existence of activator in human mixed saliva but here the authors carried a step further and studied and discovered the existence of plasmin substances in mixed saliva in association with the parotid reflexive saliva.

\section{Method and Materials}

A. Saliva.

For experimental purposes, saliva was collected of healthy male students whose oral conditions revealed no pathogenic findings, having been thoroughly rinsed prior to collection.

For the collection of parotid reflexive saliva, glass suction-cup which has completely sterilized was attached to the efferent portion of the parotid gland, in which process a few drops of $0.8 \%$ acetic acid were infused on the tongue to induce the secretion of reflexive saliva.

Saliva specimen thus collected was subjected to centrifugal treatment at $3000 \mathrm{rpm}$ for 10 minutes and the supernatant liquid was used as a material. No plasmin substances

* 永井甲子四郎, 土屋勝人, 上り口寛武, 佐野 彰信, 矢崎昌：Dept. of Physiology, Nihon Univ. School of Dentistry (Director: Associate Prof. Kineshiro Nagai). 
were detected in the sediments. The sediments were solved in potassium chloride of $2 \mathrm{M}$ to render the whole to be 5 to 10 times the original volume and after being neutralized, $0.03 \mathrm{ml}$ was precipitated onto the fibrin plate.

\section{B. Fibrin Plate.}

As fibrinogen material, use was made of bovine fibrinogen and preliminary to the test we measured its clottable protein so as to maintain the concentration of fibrin plate at a constant level. A fibrinogen borate saline buffer solution containing $0.15 \%$ of clottable protein was prepared and its $10 \mathrm{ml}$ was poured in a petrie dish, in which it was mixed with $0.5 \mathrm{ml}$ of $20 \mathrm{U} / \mathrm{ml}$ thrombin solution to be used as standard fibrin plate.

When lysis took place by the use of an ordinary plate and a heated plate respectively, the presence of plasmin could be determined and when lysis took place with the use of an ordinary plate alone, it pointed to the existence of activator. When either method failed to bring about lysis, the S. K. activation method was employed where the occurrence of lysis attested to the presence of proactivator. Three measurements were read on the short and long cycles of lysis, after 20 hours of incubation at a temperature of $37^{\circ} \mathrm{C}$, so that the mean values might be obtained.

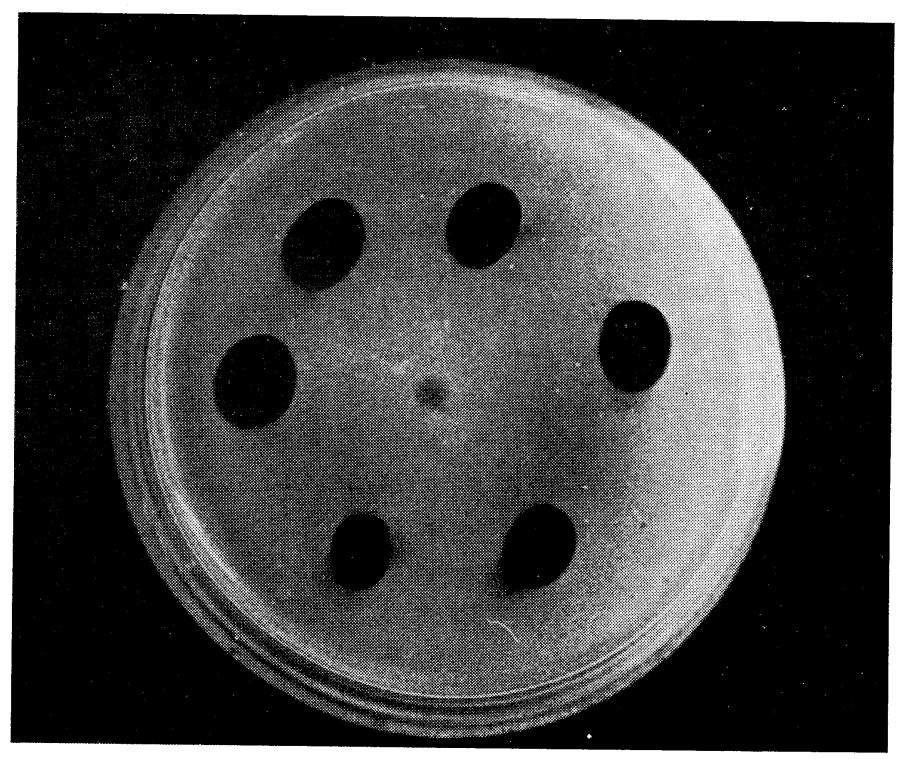

Fig. 1. An image of a perfect lysis

\section{Thrombin.}

Thrombin of 5000 units was diluted down to $20 \mathrm{~V} / \mathrm{ml}$ for our test purposes.

\section{Experimental Results}

\section{Detection of Plasmin, Activator and Proactivator in the Mixed Saliva.}

Table 1 gives the result of nearly 70 cases of fibrin plate tests on the mixed saliva to obtain lysis of the fibrin film. Of 70 , we found 6 cases to be completely soluble with the use of either an ordinary or heated fibrin plate and 4 cases had complete lysis. 
This fact conclusively points out to the presence of plasmin.

Cases which failed to solve in either of these two plates were 19 in number and this was interpreted as meaning the presence of activator.

The streptokinase activation test was conducted on those cases which failed to bring about lysis. As given in Table 2, nearly all of them showed lysis of 100 to 195, thus pointing out to the existence of proactivator.

\section{TABLE 1}

The effect of mixed saliva upon fibrin plates Zones of lysis (average $\mathrm{D}^{2}$ in $\mathrm{mm}$ )

\begin{tabular}{c|c|c|c|c}
\hline Experimental No. & Name & Mixed saliva & Unheated plate & Heated plate \\
\cline { 2 - 5 } 1 & G. I. & $0.03 \mathrm{ml}$ & 16 & - \\
2 & H. H. & $\prime \prime$ & 16 & - \\
14 & K. A. & $\prime \prime$ & 24 & - \\
23 & K. H. & $\prime \prime$ & 16 & 13 \\
24 & L. S. & $\prime \prime$ & 15 & - \\
25 & H. U. & $\prime \prime$ & 81 & 25 \\
33 & Y. U. & $\prime \prime$ & 16 & 16 \\
45 & A. T. & $\prime \prime$ & 16 & - \\
51 & T. Y. & $\prime \prime$ & 24 & - \\
70 & T. V. & $\prime \prime$ & 49 & -
\end{tabular}

* Average of triplicate determination.

TABLE 2

The effect of streptokinase plus mixed saliva on fibrin plates Zones of lysis (average $\mathrm{D}^{2}$ in $\mathrm{mm}$ )

\begin{tabular}{c|c|c|c|c|c}
\hline \multirow{2}{*}{ Ex. No. } & Name & $\begin{array}{c}\text { Concentration of } \\
\text { S. K. }\end{array}$ & Mixed saliva & $\begin{array}{c}\text { Unheated } \\
\text { plate }\end{array}$ & Heated plate \\
\cline { 2 - 3 } 3 & N. M. & 25000 & $0.5 \mathrm{ml}$ & 144 & - \\
10 & M. M. & $\prime \prime$ & $\prime \prime$ & 144 & - \\
18 & T. Y. & $\prime \prime$ & $\prime \prime$ & 100 & - \\
30 & K. S. & $\prime \prime$ & $\prime \prime$ & 195 & - \\
42 & T. T. & $\prime \prime$ & $\prime \prime$ & 122 & - \\
55 & N. S. & $\prime \prime$ & $\prime \prime$ & 168 & - \\
65 & K. A. & $\prime \prime$ & $\prime \prime$ & 130 & -
\end{tabular}

* $0.03 \mathrm{ml}$ aliquots of reaction mixture were placed on the fibrin plate

* Average of triplicate determination.

* Ex. No. : experimental number.

* S. K. : streptokinase.

\section{Detection of Plasma, Activator and Proactivator in the Pure Saliva.}

Here the parotid reflexive saliva collected of healthy males was used (Table 3). Of 45 one found 6 cases to have lysis. However, we failed to detect the presence of plasmin in these specimens even including those whose mixed saliva showed the presence 
of plasmin.

Table 4 gives the result of the S. K. activation test which was effected on the specimens of parotid reflexive saliva from the same individuals that did not show lysis under either of an ordinary or heated fibrin plate. The presence of proactivator is certainly attested to.

TABLE 3

The effect of pure saliva upon fibrin plates

Zones of lysis (average $\mathrm{D}^{2}$ in $\mathrm{mm}$ )

\begin{tabular}{c|c|c|c|c}
\hline Ex. No. & Name & Pure saliva & Unheated plate & Heated plate \\
\cline { 2 - 4 } 6 & H. H. & $0.03 \mathrm{ml}$ & 36 & - \\
12 & M. M. & $\prime \prime$ & 42 & - \\
17 & M. T. & $\prime \prime$ & 36 & - \\
22 & T. Y. & $\prime \prime$ & 40 & - \\
35 & K. K. & $\prime \prime$ & 38 & - \\
45 & N. Y. & $\prime \prime$ & 64 & -
\end{tabular}

* Average of triplicate determination.

* Ex. No. : experimental number.

TABLE 4

The effect of streptokinase plus saliva on fibrin plates Zones of lysis (average $\mathrm{D}^{2}$ in $\mathrm{mm}$ )

\begin{tabular}{c|c|c|c|c|c}
\hline \hline \multirow{2}{*}{ Ex. No. } & Name & $\begin{array}{c}\text { Concentration of } \\
\text { S. K. }\end{array}$ & Pure saliva & $\begin{array}{c}\text { Unheated } \\
\text { plate }\end{array}$ & Heated plate \\
\cline { 1 - 5 } 1 & N. M. & 25000 & $0.5 \mathrm{ml}$ & 240 & - \\
2 & M. M. & $\prime \prime$ & $\prime \prime$ & 506 & - \\
3 & T. M. & $\prime \prime$ & $\prime \prime$ & 252 & - \\
11 & M. M. & $\prime \prime$ & $\prime \prime$ & 300 & - \\
14 & T. M. & $\prime \prime$ & $\prime \prime$ & 182 & - \\
40 & M. N. & $\prime \prime$ & $\prime \prime$ & 180 & -
\end{tabular}

$* 0.03 \mathrm{ml}$ aliquots of reaction mixture were placed on the fibrin plate.

* Average of triplicate determination.

* Ex. No. : experimental number.

\section{Detection to Plasmin, Activator and Proactivator in the Mixed and the Pure Saliva in the Same Individuals.}

Two sets of saliva, pure and mixed, were collected from the same individuals extending for the same interval. They were tested by means of an ordinary and heated fibrin plates (Table 5).

The parotid reflexive saliva collected of the same individuals which had not occasioned lysis phenomenon under an ordinary or heated plates was subjected to the S. K. activation test and, as a result, it was determined that proactivator existed in it, as was the case with the experiments I and II. 
TABLE 5

The effect of pure saliva and mixed saliva upon fibrin plates Zones of lysis (average $\mathrm{D}^{2}$ in $\mathrm{mm}$ )

\begin{tabular}{|c|c|c|c|c|c|}
\hline Ex. No. & Name & $\begin{array}{l}\text { Pure } \\
\text { saliva }\end{array}$ & $(\mathrm{P}), \underset{\text { saliva }}{\operatorname{Mixed}}(\mathrm{M})$ & Unheated plate & Heated plate \\
\hline 1 & G. I. & & $0.03 \mathrm{ml}$ & $\begin{array}{l}\text { P. } \\
\text { M. }\end{array}$ & - \\
\hline 3 & H. H. & & "I & $\begin{array}{l}\text { P. } \\
\text { M. - }\end{array}$ & - \\
\hline 23 & K. H. & & " & $\begin{array}{l}\mathrm{P} . \\
\mathrm{M} .\end{array}$ & $\overline{13}$ \\
\hline 31 & T. K. & & $\prime \prime$ & $\begin{array}{l}\text { P. } \quad 36 \\
\text { M. }\end{array}$ & - \\
\hline 33 & Y. M. & & " & P. $\overline{\text { M. }}$ & $\overline{16}$ \\
\hline 35 & K. K. & & " & $\begin{array}{l}\text { P. } \quad 38 \\
\text { M. } \quad-\end{array}$ & - \\
\hline 45 & N. Y. & & '" & $\begin{array}{ll}\text { P. } & 64 \\
\text { M. } & -\end{array}$ & - \\
\hline
\end{tabular}

* Average of triplicate determination.

* Ex. No. : experimental number.

\section{Considerations}

As a result of a series of experiments undertaken by the authors, it has been made clear that there exist plasmin, activator and proactivator in salive. As regards mixed saliva, plasmin substances are found in 19 cases out of 70 cases tested as given in Table 1. The existence of proactivator is attested in the same salive by means of the S.K. activation method in all the specimens. In pure saliva, the existence of activator is attested to in 6 saliva specimens out of 45 . Some specimens which did not show the existence of activator were found by the S. K. activation to possess the existence of proactivator in them, though plasmin was not found. Based on these various findings, it has been concluded that salivary plasmin is derived from the parotid gland.

The following list summarizes the appearance frequency of plasmin substances in human saliva.

$\begin{array}{lccc} & \text { Proactivator } & \text { Activator } & \text { Plasmin } \\ \text { Mixed saliva } & 100 \% & 26 \% & 9 \% \\ \text { Pure saliva } & 100 \% & 11 \% & 0 \%\end{array}$

\section{Conclusion}

The present study has enabled the authors to reach at the conclusion as follows.

1) Both activator and proactivator exist in the mixed saliva.

2) In addition to the parotid gland, the derivation of plasmin may be sought in the oral mucosa or in other glands.

3) Of activator and proactivator found in the parotid reflexive saliva, the amount of the latter far exceeds that of the former. However, under the S. K. activation test the existence of these substances is confined to a relatively few cases. 
Note :

This study is here published in the form of an abstract and will be followed by a more complete report in due course of time.

\section{References}

[1] Dastre, A. : Fibrinolyse dans le sang, Arch. de physiol., (1893) Paris.

[2] Nolf, P. : Des modifications de la coagulation du sang chez le chien après extirpation du foie, Arch. de physiol., (1905) Paris.

[3] UChidA, S.: An Application of Amino-caproic Acid in Internal Medicine as Antiplasmin Drug, Clinical Med., and Pediat., 18: 8, (1963) Tokyo.

[4] Okamoto, A. : Bleeding and Plasmin, Jour., of Otorhino., 33 : 4, 90, (1961) Tokyo.

[5] ItOGA, G. and Yogo, T. : The Inhibitoyo Effect of Ipsilon Amino-caproic Acid on the Tuberculin Reaction, Keio J. Med., 8 : 299, (1959) Tokyo.

[6] Watanabe, N.: On the Behavior of Plasmin in the Allergic Mechanism, Allergy, 1: 70, (1962) Tokyo.

[7] Ole, K.: Fibrinolytic Activity in Human Saliva, Acta Phys. Scandinav., 34 : 138, (1955) Upsala. 